\title{
PENGARUH PENDEKATAN PEMBELAJARAN CONTEXTUAL TEACHING AND LEARNING (CTL) TERHADAP PENINGKATAN HASIL BELAJAR KONSEP STRUKTUR DAN FUNGSI BAGIAN TUMBUHAN KELAS IV SD
}

\author{
Herfiani, Syarifuddin \\ Pendidikan Guru Sekolah Dasar, Fakultas Keguruan dan Ilmu Pendidikan \\ Universitas Muhammadiyah Makassar \\ Iqramsyar34@gmail.com
}

\begin{abstract}
ABSTRAK
Jenis penelitian ini adalah penelitian pra-eksperimen bentuk Pre Test Post Test Design yaitu sebuah eksperimen yang dalam pelaksanaannya hanya melibatkan satu kelas sebagai kelas eksperimen tanpa adanya kelas pembanding (kelas kontrol) yang bertujuan untuk mengetahui Pengaruh Pendekatan Pembelajaran Contextual Teaching and Learning (CTL) terhadap Peningkatan Hasil Belajar Konsep Struktur dan Fungsi Bagian Tumbuhan di Kelas IV SD Inpres Minasa Upa 1 Kota Makassar tahun ajaran 2016/2017. Satuan eksperimen dalam penelitian ini adalah siswa Kelas IV sebanyak 30 orang. Penelitian dilaksanakan selama 5 kali pertemuan. Keberhasilan proses pembelajaran ditinjau dari aspek, yaitu: ketercapaian ketuntasan hasil belajar siswa secara klasikal, aktivitas siswa dalam pembelajaran. Pembelajaran dikatakan berhasil jika aspek di atas terpenuhi. Teknik pengumpulan data yang digunakan adalah data hasil belajar siswa yang dikumpulkan dengan menggunakan tes hasil belajar, data tentang aktivitas siswa dalam pembelajaran dikumpulkan dengan menggunakan lembar observasi aktivitas belajar siswa. Hasil analisis statistik deskriptif terhadap Pengaruh Pendekatan Pembelajaran Contextual Teaching and Learning (CTL) terhadap Peningkatan Hasil Belajar Konsep Struktur dan Fungsi Bagian Tumbuhan ini menunjukkkan hasil belajar yang lebih baik dari pada sebelum menggunakan pendekatan CTL. Hasil analisis statistik inferensial menggunakan rumus uji $\mathrm{t}$, diketahui bahwa nilai $\mathrm{t}$ Hitung yang diperoleh adalah 7,75 dengan frekuensi $\mathrm{dk}=30-1=29$, pada taraf signifikansi $50 \%$ diperoleh $t_{\text {Tabel }}=2,04$. Jadi, $t_{\text {Hitung }}>t_{\text {tabel }}$ atau hipotesis alternative $\left(\mathrm{H}_{1}\right)$ diterima. Hal ini membuktikan bahwa pendekatan CTL berpengaruh terhadap peningkatan hasil belajar konsep struktur dan fungsi bagian tumbuhan.
\end{abstract}

Kata kunci: Pendekatan Contextual Teaching and Learning (CTL ) 


\section{PENDAHULUAN}

Pendidikan adalah usaha sadar dan terencana untuk mewujudkan suasana belajar dan proses pembelajaran agar siswa secara aktif mengembangkan potensi dirinya. Untuk memiliki pengendalian diri, kepribadian, kecerdasan, akhlak mulia, serta keterampilan yang diperlukan dalam masyarakat yang berguna bagi bangsa dan negara.

Sebagai guru profesional hendaknya dapat memilih dan menerapkan model atau metode pembelajaran yang efektif agar materi yang diajarka oleh guru dapat dipahami dengan baik serta dapat meningkatkan hasil belajar. Dengan demikian, memilih strategi pembelajaran diharapkan pencapaian tujuan belajar dapat terpenuhi sebagai mana yang diharapkan.

Rendahnya hasil belajar siswa dikarenakan mereka belum bisa menghubungkan antara apa yang mereka pelajari dan bagaimana pengetahuan Itu akan digunakan, cara mereka memperoleh informasi dan motivasi diri belum tersentuh oleh metode yang betul-betul bisa membantu mereka. Para siswa kesulitan untuk memahami konsep-konsep akademis karena metode mengajar yang digunakan selama ini oleh guru hanya terbatas pada metode ceramah. Oleh karena itu diperlukan suatu metode yang benar-benar bisa memberi jawaban dari masalah ini. Salah satu metode yang bisa lebih memberdayakan siswa adalah pendekatan kontekstual atau Contextual Teaching and Learning (CTL).

Contextual Teaching and Learning (CTL) adalah sistem pembelajaran yang cocok dengan kinerja otak, untuk menyusun pola-pola yang mewujudkan makna, dengan cara menghubungkan muatan akademis dengan konteks kehidupan sehari-hari siswa. Hal ini penting diterapkan agar informasi yang diterima tidak hanya disimpan dalam memori jangka pendek tetapi dapat disimpan dalam memori jangka panjang sehingga akan dihayati dan diterapkan dalam tugas pekerjaan.

CTL disebut pendekatan kontekstual karena konsep belajar membantu guru mengaitkan antara materi yang diajarkan dengan situasi dunia nyata siswa dan mendorong siswa membuat hubungan antara pengetahuan yang dimilikinya dengan penerapannya dalam kehidupan mereka sebagai anggota masyarakat.

Menurut teori pembelajaran kontekstual, pembelajaran terjadi hanya 
ketika siswa memproses informasi atau pengetahuan baru sedemikian rupa sehingga dapat terserap kedalam benak mereka dan mereka mampu menghubungkannya dengan kehidupan nyata yang ada disekitar mereka. Pendekatan ini mengasumsikan bahwa pikiran secara alami akan mencari makna dari hubungan individu dengan lingkungan sekitarnya.

Berdasarkan uraian di atas rumusan masalah dalam penelitian ini adalah "Apakah Pengaruh Pendekatan Pembelajaran Contextual Teaching and Learning (CTL) Terhadap Peningkatan Hasil Belajar Siswa pada Pokok Bahasan Struktur dan Fungsi Bagian Tumbuhan di Kelas IV SD Inpres Minasa Upa 1 Kota Makassar ?". Tujuan penelitian ini adalah untuk mengetahui apakah Pengaruh Pendekatan Pembelajaran Contextual Teaching and Learning (CTL) Terhadap Peningkatan Hasil Belajar Siswa pada Pokok Bahasan Struktur dan Fungsi Bagian Tumbuhan di Kelas IV SD Inpres Minasa Upa 1 Kota Makassar .

\section{a. Strategi Pembelajaran Kontekstual}

Menurut Kunandar (2007: 272) mengemukakan bahwa strategi pembelajaran kontekstual adalah suatu strategi pembelajaran yang menekankan kepada:
1) Menekankan kepada proses keterlibatan siswa secara penuh untuk dapat menemukan materi yang dipelajari dan menghubungkannya dengan situasi kehidupan nyata sehingga mendorong siswa untuk dapat menerapkannya dalam kehiduapn mereka.

2) CTL menekankan kepada proses keterlibatan siswa untuk menemukan materi, artinya proses belajar diorientasikan pada proses pengalaman secara langsung. Proses belajar dalam kontekstual tidak mengharapkan agar siswa hanya menerima pelajaran, akan tetapi proses mencari dan menemukan sendiri materi pelajaran.

3) CTL mendorong siswa dapat menemukan hubungan antara materi yang dipelajari dengan situasi kehidupan nyata, artinya siswa dituntut untuk dapat menangkap antara pengalaman belajar di sekolah dengan kehidupan nyata, hal ini sangat penting sebab dengan mengorelasikan materi yang ditemukan dengan kehidupan nyata bukan saja bagi siswa materi itu akan bermakna secara fungsional, 
akan tetapi materi yang dipelajarinya akan tertanam erat dalam memori siswa, sehingga tidak akan mudah dilupakan.

4) CTL mendorong siswa untuk dapat menerapkannya dalam kehidupan, artinya CTL bukan hanya mengharapkan siswa dapat memahami materi yang dipelajarinya, akan tetapi bagaimana materi pelajaran itu dapat mewarnai perilakunya dalam kehidupan sehari-hari.

\section{Pembelajaran IPA di Sekolah Dasar}

Pengertian ilmu pengetahuan alam, biasa disebut IPA adalah sebuah mata pelajaran yang mempelajari ilmu awan untuk siswa Sekolah Dasar, dan Sekolah Menengah Tingkat Pertama, dalam ilmu pengetahuan, istilah Ilmu Pengetahuan Alam merujuk pada pendekatan logis untuk mempelajari alam semesta.

Pendidikan IPA merupakan salah satu aspek penting yang perlu di ajarkan kepada para siswa di sekolah. Tidak heran apa bila mata pelajaran ini kemudian diberikan sejak masih di bangku SD.

Adapun Wahyana mengatakan bahwa IPA adalah suatu kumpulan pengetahuan tersusun secara sistematik, dan dalam pengunaannya secara umum terbatas pada gejalagejala alam.

Dari penjelasan diatas dapat disimpulkan bahwa IPA adalah suatu kumpulan teori sistematis, penerapannya secara umum terbatas pada gejala-gejala alam, lahir dan berkembang melalui metode ilmiah seperti observasi dan eksperimen serta menuntut sikap ilmiah seperti rasa ingin tahu, terbuka dan jujur.

\section{METODE PENELITIAN}

Penelitian ini merupakan penelitian eksperimen dengan jenis penelitian PreEksperimental Design yang dipandang sebagai penelitian yang tidak sebenarnya. Jenis Eksperimen ini dilaksanakan pada satu kelompok saja tanpa kelompok pembanding.

Dalam penelitian ini yang menjadi populasi adalah semua siswa SD Inpres Minasa Upa 1 Kota Makassar yang berjumlah 318 dan sampel dalam penelitian ini adalah kelas IV yang berjumlah 30 siswa. Instrumen yang digunakan dalam penelitian ini adalah Tes dan Observasi. Analisis data yang digunakan dua teknik statistik, yaitu statistik deskriptif dan statistik inferensial. 
HASIL PENELITIAN DAN PEMBAHASAN

Pengaruh Pendekatan CTL Terhadap

Peningkatan Hasil Belajar Konsep

Struktur dan Fungsi Bagian

Tumbuhan di Kelas IV SD Inpres

Minasa Upa 1 Kota Makassar

Sesuai dengan hipotesis penelitian yakni "pengaruh pendekatan CTL Terhadap Peningkatan Hasil Belajar Konsep Struktur dan Fungsi Bagian Tumbuhan di Kelas IV SD Inpres Minasa Upa 1 Kota Makassar". maka teknik yang digunakan untuk menguji hipotesis tersebut adalah teknik statistik inferensial dengan menggunakan uji-t.

Tabel Analisis skor Pre-test dan Post-

test

\begin{tabular}{|l|c|c|c|c|}
\hline No & $\begin{array}{l}\mathrm{X} 1 \\
(\text { Pre- } \\
\text { test })\end{array}$ & $\begin{array}{l}\mathrm{X} 2 \\
(\text { Post- } \\
\text { test })\end{array}$ & $\begin{array}{l}\mathrm{d}=\mathrm{X} 2- \\
\mathrm{X} 1\end{array}$ & $\mathrm{~d}^{2}$ \\
\hline 1 & 40 & 55 & 15 & 225 \\
\hline 2 & 40 & 70 & 30 & 900 \\
\hline 3 & 45 & 65 & 20 & 400 \\
\hline 4 & 40 & 80 & 40 & 1600 \\
\hline 5 & 45 & 80 & 35 & 1225 \\
\hline 6 & 65 & 80 & 15 & 225 \\
\hline 7 & 40 & 85 & 45 & 2025 \\
\hline 8 & 40 & 75 & 35 & 1225 \\
\hline 9 & 85 & 75 & -10 & 100 \\
\hline 10 & 60 & 90 & 30 & 900 \\
\hline
\end{tabular}

\begin{tabular}{|c|c|c|c|c|}
\hline 11 & 70 & 70 & - & - \\
\hline 12 & 40 & 60 & 20 & 400 \\
\hline 13 & 40 & 60 & 20 & 400 \\
\hline 14 & 40 & 80 & 40 & 1600 \\
\hline 15 & 50 & 70 & 20 & 400 \\
\hline 16 & 65 & 90 & 25 & 625 \\
\hline 17 & 65 & 70 & 5 & 25 \\
\hline 18 & 40 & 70 & 30 & 900 \\
\hline 19 & 60 & 75 & 15 & 225 \\
\hline 20 & 70 & 75 & 5 & 25 \\
\hline 21 & 60 & 70 & 10 & 100 \\
\hline 22 & 75 & 80 & 5 & 25 \\
\hline 23 & 40 & 70 & 30 & 900 \\
\hline 24 & 75 & 70 & -5 & 25 \\
\hline 25 & 90 & 90 & - & - \\
\hline 26 & 70 & 90 & 20 & 400 \\
\hline 27 & 40 & 60 & 20 & 400 \\
\hline 28 & 55 & 90 & 35 & 1225 \\
\hline 29 & 60 & 80 & 20 & 400 \\
\hline 30 & 45 & 80 & 35 & 1225 \\
\hline & 1650 & 2255 & 605 & 18125 \\
\hline
\end{tabular}

Langkah-langkah dalam pengujian hipotesis adalah sebagai berikut :

1. Mencari harga "Md" dengan menggunakan rumus:

$$
\begin{aligned}
\text { Md } & =\frac{\sum d}{N} \\
& =\frac{605}{30}
\end{aligned}
$$


$=20,16$

2. Mencari harga " $\sum X^{2} d$ " dengan menggunakan rumus:

$$
\begin{aligned}
\sum X^{2} d & =\sum d^{2}-\frac{\left(\sum d\right)^{2}}{N} \\
& =18125-\frac{(605)^{2}}{30} \\
& =18125 \\
- & \frac{366025}{30} \\
& =18125-12200,83 \\
& =5924,17
\end{aligned}
$$

3. Menentukan harga $t_{\text {Hitung }}$

$$
\begin{aligned}
& \mathrm{t}=\frac{M d}{\sqrt{\frac{\sum X^{2} d}{N(N-1)}}} \\
& \mathrm{t}=\frac{20,16}{\sqrt{\frac{5924,17}{30(30-1)}}} \\
& \mathrm{t}=\frac{20,16}{\sqrt{\frac{5924,17}{870}}} \\
& \mathrm{t}=\frac{20,16}{\sqrt{6,809}} \\
& \mathrm{t} \quad=\frac{20,16}{2,60} \\
& \mathrm{t} \quad=7,75
\end{aligned}
$$

4. Menentukan harga $t_{\text {Tabel }}$

Untuk mencari $t$ Tabel peneliti menggunakan tabel distribusi t dengan taraf signifikan $\alpha=0,05$ dan $d k=N-$ $1=30-1=29$ maka diperoleh $t_{0,05}=$ 2,04. Setelah diperoleh $t_{\text {Hitung }}=7,75$ dan $\mathrm{t}_{\text {Tabel }}=2,04$ maka diperoleh $\quad t_{\text {Hitung }}>$ $t_{\text {Tabel }}$ atau 7,75> 2,04. Sehingga dapat disimpulkan bahwa $\mathrm{H}_{1}$ diterima. Ini berarti bahwa pendekatan CTL berpengaruh terhadap peningkatan hasil belajar konsep struktur dan fungsi bagian tumbuhan.

Pendekatan Contextual Teaching and Learning (CTL) merupakan konsep belajar yang membantu guru mengaitkan antara materi yang diajarkan dengan situasi dunia nyata siswa dan mendorong siswa membuat hubungan antara pengetahuan yang dimilikinya dengan penerapannya dalam kehidupan mereka sebagai anggota masyarakat. Menurut teori pembelajaran kontekstual, pembelajaran terjadi hanya ketika siswa memproses informasi atau pengetahuan baru sedemikian rupa sehingga dapat terserap kedalam benak mereka dan mereka mampu menghubungkannya dengan kehidupan nyata yang ada disekitar mereka. Pendekatan ini mengasumsikan bahwa pikiran secara alami akan mencari makna dari hubungan individu dengan lingkungan sekitarnya.

Berdasarkan hasil pre-test, nilai rata-rata hasil belajar siswa yaitu sangat rendah 46,66\%, rendah $6,66 \%$ dan $13,33 \%$, sedang $16,66 \%$, tinggi $3,33 \%$ dan sangat tingggi berada pada presentase 3,33\%. Melihat dari hasil presentase yang ada dapat dikatakan bahwa tingkat kemampuan siswa dalam memahami serta penguasaan konsep 
struktur dan fungsi bagian tumbuhan sebelum menggunakan pendekatan CTL tergolong rendah.

Selanjutnya nilai rata-rata hasil post-test adalah 75 . Jadi hasil belajar setelah menggunakan pendekatan CTL mempunyai hasil belajar yang lebih baik dibanding dengan sebelum menggunakan pendekatan CTL. Selain itu persentasi kategori hasil belajar siswa juga meningkat yakni sangat tinggi yaitu $16,66 \%$, tinggi $26,66 \%$, sedang $40 \%$, rendah 3,33\% dan 13,33\%, dan sangat rendah berada pada presentase $0,00 \%$.

Berdasarkan hasil analisis statistik inferensial dengan menggunakan rumus uji $t$, dapat diketahui bahwa nilai $t_{\text {hitung }}$ sebesar 7,75. Dengan frekuensi (dk) sebesar 30 $1=29$, pada taraf signifikansi $5 \%$ diperoleh $t_{\text {tabel }}=2,04$. Oleh karena $t_{\text {hitung }}$ $>t_{\text {tabel }}$ pada taraf signifikansi 0,05 , maka hipotesis alternative $\left(\mathrm{H}_{1}\right)$ diterima yang berarti bahwa penggunaan media gambar berpengaruh terhadap kemampuan menulis karangan deskripsi.

Hasil analisis diatas yang menunjukkan adanya pengaruh pendekatan CTL terhadap peningkatan hasil belajar konsep struktur dan fungsi bagian tumbuhan, sejalan dengan hasil observasi yang dilakukan. Berdasarkan hasil observasi terdapat perubahan pada siswa dimana pada awal kegiatan pembelajaran ada beberapa siswa yang melakukan kegiatan lain atau bersikap cuek selama pembelajaran berlangsung. Hal ini dapat dilihat pada pertemuan pertama siswa yang melakukan kegiatan lain sebanyak 8 orang, sedangkan pada pertemuan terakhir hanya 3 siswa yang melakukan kegiatan lain pada saat guru menjelaskan materi. Pada awal pertemuan, hanya sedikit siswa yang aktif pada saat pembelajaran berlangsung. Akan tetapi sejalan dengan digunakannya media pembelajaran siswa mulai aktif pada setiap pertemuan.

Hasil observasi menunjukkan banyaknya jumlah siswa yang menjawab pada saat diajukan pertanyaan dan banyaknya jumlah siswa yang mampu menyimpulkan materi pembelajaran. Proses pembelajaran yang menyenangkan membuat siswa tidak lagi melakukan kegiatan lain pada saat pembelajaran berlangsung.

Berdasarkan hasil analisis statistik deskriptif dan statistik inferensial yang diperoleh serta hasil observasi yang telah dilakukan, dapat disimpulkan bahwa pendekatan CTL 
berpengaruh terhadap peningkatan hasil belajar konsep struktur dan fungsi bagian tumbuhan di kelas IV SD Inpres Minasa Upa 1 Kota Makassar.

\section{KESIMPULAN DAN SARAN}

Berdasarkan data yang diperoleh dapat disimpulkan bahwa secara umum hasil belajar kelas V B SDN Bulurokeng 1 Makassar sebelum menggunakan media gambar dikategorikan rendah. Hal ini ditunjukkan dari perolehan persentase hasil belajar siswa yaitu sangat rendah $46,66 \%$, rendah $6,66 \%$ dan 13,33\%, sedang 16,66\%, tinggi $3,33 \%$ dan sangat tingggi berada pada presentase 3,33\%. Berdasarkan data yang diperoleh dapat disimpulkan bahwa secara umum hasil belajar kelas V B SDN Bulurokeng 1 Makassar sesudah menggunakan media gambar dikategorikan tinngi, dapat dilihat dari perolehan persentase yaitu sangat tinggi yaitu $16,66 \%$, tinggi $26,66 \%$, sedang $40 \%$, rendah $3,33 \%$ dan $13,33 \%$, dan sangat rendah berada pada presentase $0,00 \%$. Berdasarkan uji hipotesis yang telah dilakukan dapat disimpulkan bahwa penggunaan media gambar berpengaruh terhadap kemampuan menulis karangan deskripsi siswa kelas $\mathrm{V}$ B $\quad$ SDN
Bulurokeng 1 Makassar, setelah diperoleh $t_{\text {Hitung }}=7,75$ dan $t_{\text {Tabel }}=2,04$ maka diperoleh $t_{\text {Hitung }}>t_{\text {Tabel }}$ atau 7,75> 2,04 .

Saran yang dapat diberikan Kepada para pendidik khususnya guru SDN Bulurokeng 1 Makassar, disarankan untuk menggunakan media pembelajaran dalam pembelajarannya agar dapat membangkitkan minat dan motivasi siswa untuk belajar. Kepada peneliti lain, diharapkan mampu mengembangkan media pembelajaran ini pada mata pelajaran lain demi tercapainya tujuan yang diharapkan. Kepada calon peneliti, akan dapat mengembangkan media pembelajaran ini serta memperkuat hasil penelitian ini dengan cara mengkaji terlebih dahulu dan mampu mengadakan penelitian yang lebih sukses.

\section{DAFTAR PUSTAKA}

Djamal, Syaiful Bahri. 2008. Psikologi Belajar. Jakarta: Rineksi Cipta.

Djam'an Satori, dkk. 2008. Profesi Keguruan. Jakarta: Universitas Terbuka.

Kunandar. 2007. Guru Profesional. Jakarta: PT Raja Grafindo Persada.

Nurhadi, dkk. 2003. Pembelajaran Kontekstual dan Penerapannya dalam KBK. Malang: Universitas Negeri Malang. 
Panut. 2006. Ilmu Pengetahuan Alam. Bogor: Perpustakaan Nasional.

Sanjaya, Wina. 2007. Strategi Pembelajaran. Jakarta: Kencana Prenada Media Grup.

Sanjaya, Wina. 2007; Strategi Pembelajaran. Berorientasi Standar Proses Pendidikan. Jakarta: Kencana.

Soekamto, Toeti. 2000. Teori Belajar dan Model Pembelajaran. Jakarta: PAU-PPAI, Universitas Terbuka.

Sofyan, Gusarmin dan Amiruddin B. 2007. Modul Diklat Profesi Guru Model-Model Pembelajaran I. Kendari: Universitas Haluoleo.

Trianto. 2007. Model-model Pembelajaran Berorientasi Inovatif Jakarta: Prestasi Pustaka
Sudjana. 2005. Metode Statistik. Bandung: Tarsito.

Sugiyono. 2008. Metode Statistika. Bandung: Taristo.

Tim Penyusun FKIP Unismuh Makassar. 2012. Pedoman Penulisan Skripsi. Makassar. Panrita Press.

https://amaliahnurjannah.files.wordpre ss.com/2013/05/downloadmetode-penelitianeksperimen.pdf

http://gudangartikels.blogspot.com/20 13/01/hakikat-pembelajaranipa.html

(http:/<< Blog Archive $>>$ penelitian eksperimen html. 